\title{
The Primacy of the Perceptual Experience in Maurice
} Merleau-Ponty ${ }^{1}$

Alessandro Ballabio

Universidad Pedagógica Nacional, Bogotá

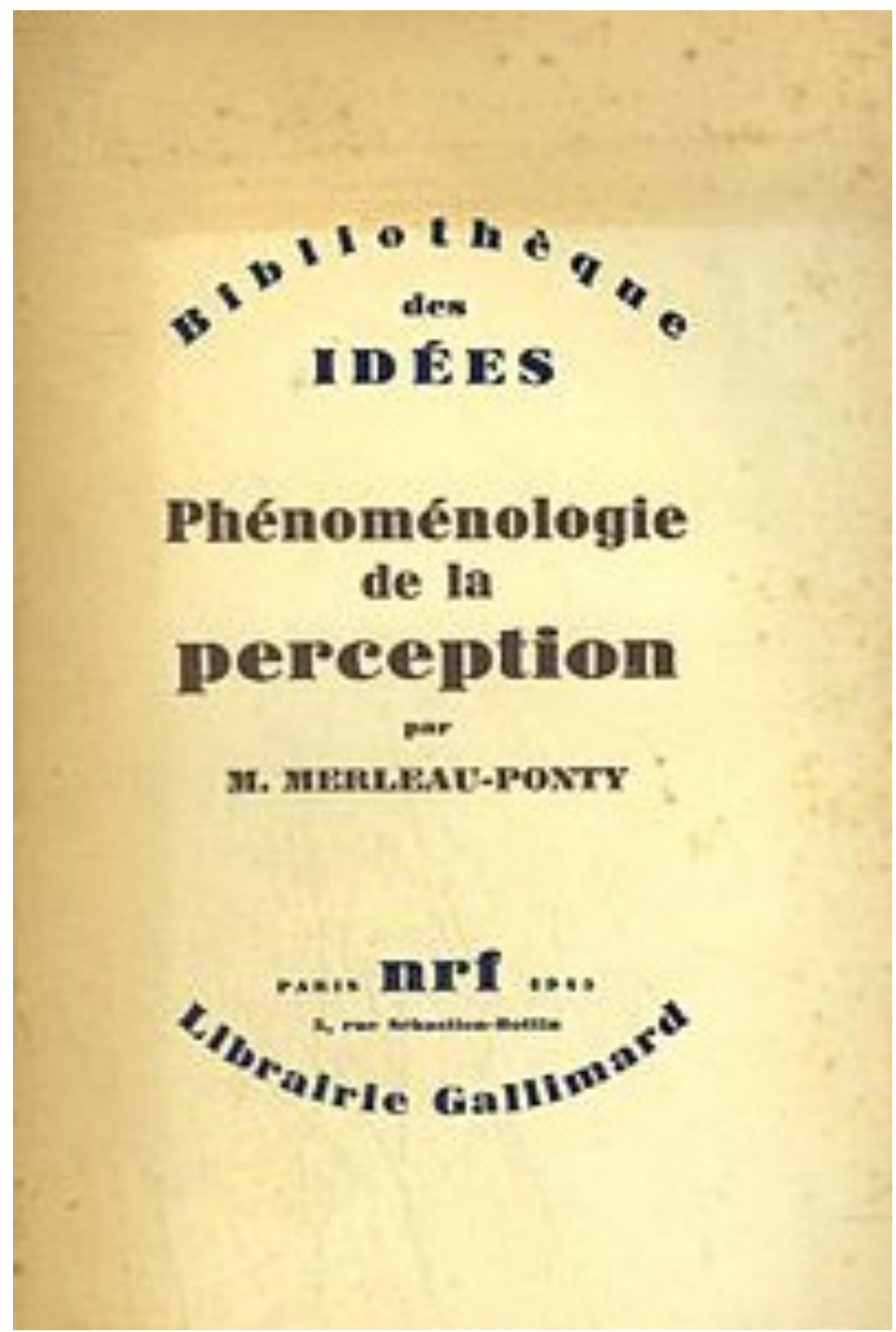

1 This paper is the English translation of two paragraphs (V and VI) of the fourth chapter of my book Experiencia y creatividad en C. S. Peirce y M. Merleau-Ponty (2016), which sums up the results of my Ph.D. Dissertation "Los bordes de la experiencia creativa en C. S. Peirce y M. Merleau-Ponty" (2016). 


\section{Resumo}

Le primat de la perception et ses conséquences philosophiques (1946) é a transcrição do debate que MerleauPonty teve em dia 23 de novembro de 1946, na Société française de Philosophie, em relação aos resultados da Phénoménologie de la perception (1945). Merleau-Ponty aponta ao fato de que a percepção não é um objetivo intellectual, mas a síntese prática que implica o movimento do corpo, como a origem da experiência perceptive do mundo.

\section{Palavras-chave}

Merleau-Ponty. Percepção. Experiência. Gesto. Corpo.

\section{Abstract}

Le primat de la perception et ses conséquences philosophiques (1946) is the transcription of the discussion that Merleau-Ponty had on November 23, 1946, at the Société française de Philosophie on the results of Phénoménologie de la perception (1945). Merleau-Ponty states that perception is not an intellectual but a practical synthesis that implies the movement of the body, as the origin of the perceptual experience of the world.

\section{Keywords}

Merleau-Ponty. Perception.

\section{The practical Primacy of Perception.}

Le primat de la perception et ses conséquences philosophiques $(1946)^{1}$ is the transcription of the discussion that Merleau-Ponty had on November 23, 1946, at the Société française de Philosophie on the results of Phénoménologie de la perception (1945). The starting point of the discussion is Merleau-Ponty's thesis according to which the perceived world implies a certain type of relationships that have been unknown to the psychologist and the philosopher for a long time. If we consider the objects that remain outside our visual field, such as those located behind us, or rather the invisible profiles, interior or posterior, of a perceived thing, how can the existence of these hidden objects or the indirect perception of these invisible aspects of the object be described? "How should we describe the

\footnotetext{
${ }^{1}$ From now on I will quote Merleau-Ponty's works with the following abbreviations: [SB] The Structure of Behavior. Boston: Beacon Press (1963); [PRI] The Primacy of Perception and Its Philosophical Consequences. Evanston: Nothwestern Universtity Press (1964); [PP] Phenomenology of Perception. London and New York: Routledge (2005). 
existence of these absent objects or the non-visible parts of present objects?" (PRI: 13).

Psychologists consider this class of hidden objects or absent profiles as representations of fantasy, imagination or memory and, concisely, as objects with a mental or purely possible existence, but not actual. And nevertheless, if these invisible aspects are mere representations, they are not supposed to be perceived as existing because the represented object is not perceived as a presence: it is as if it were existing but it is not, being purely possible. These invisible aspects are not mere representations of fantasy, but profiles co-perceived and placed behind what is seen, and that is evident for at least two reasons. First of all, the profile seen is the profileof an object, that is to say, it is a part of an already given whole, which is the object itself. Therefore, what is first learned by perception is the unity and wholeness of the thing perceived in its present and absent fragments, and not a sum of present profiles added to absent representations. If it were not possible to grasp the whole object at first glance, it would be impossible to distinguish its parts after. Secondly, it is evident that these invisible fragments exist behind what is perceived directly and are not imaginary representations, because I can move towards them with my vision or touch: "but since the unseen sides of this lamp are not imaginary, but only hidden from view (to see them it suffices to move the lamp a little bit), I cannot say that they are representations" (PRI: 13-4).

Now, having excluded the fantastic and imaginary nature of the invisible aspects of the object, how should they be considered? Should they be considered as the necessary anticipations or deductions of the geometric definition of the perceived object? For instance, the front sides of a cube could be observed and afterwards the existence of the back sides 
could be deduced from its geometrical definition: $a$ body formed by six square sides, congruent and arranged in parallel. On the basis of this definition, I could anticipate how the unseen sides might be perceived by surrounding or touching the cube with my hands. Thus, I could state through geometry that those absent profiles would exist and become present to me according to a necessary geometrical law: "if, for example, I look at a cube, knowing the structure of the cube as it is defined in geometry, I can anticipate the perceptions which this cube will give me while I move around it. Under this hypothesis I would know the unseen side as the necessary consequence of a certain law of the development of my perception" (PRI: 14). In summary, the totality and unity of the perceived object would depend on an a priori and intellectual judgment on it - the geometric definition - and its perception would consist in the mere verification, confirmed or denied, of the hypothesis previously given. This conception of perception is characteristic of science: the percept is a mosaic of stimuli organized in a form by a hypothesisdefinition formulated by a judgment. A sensory stimulus raises a perception that develops according to a necessary form established by a law of the intellect: first comes the stimulus that causes a perception to which the scientific formalization is thereafter applied. This is not the way in which Merleau-Ponty conceives the primacy of perception. What meaning should be attributed to this expression? To begin with, it is worth mentioning that Merleau-Ponty regards science's view of perception as completely inadequate: "I have said that the point of view of the scientist with respect to perception-a stimulus en soi which produces a perception-is, like all forms of naive realism, absolutely insufficient. Philosophically, I do not believe that this image of perception is ultimately 
defensible" (PRI: 38-9).

Merleau-Ponty is convinced that it is not possible for the existence of the inaccessible aspects of direct perception to be generated by a judgment of the intellect: the statement It is true that the front side always implies the back one does not make the invisible visible. This formulation expressed by the judgment It is true does not correspond to what is given in my perception, which does not offer me geometrical truths about the object, but its presence in flesh and blood: "but this formula, It is true, does not correspond to what is given to me in perception. Perception does not give me truths like geometry but presences" (PRI: 14). The hidden profile of the object is present and close to me according to a certain style and it is not merely a possible perception or an intellectual synthesis that reproduces its invisible existence beyond the visible one: "thus I should not say that the unseen sides of objects are simply possible perceptions, nor that they are the necessary conclusions of a kind of analysis or geometrical reasoning" (PRI: 14).

It is important to clarify now in what sense Merleau-Ponty speaks about the primacy of perception. In answering this question, it is opportune to consider that the perceived object is given as present in all its visible and invisible aspects; the judgment of the intellect does not transform the apparent sensations of perception into the objective truths of science; the values of the world of culture are not false feelings, calculated by scientific or philosophical reason, or by reflection in general: "by these words, the primacy of perception, we mean that the experience of perception is our presence at the moment when things, truths, values are constituted for us" (PRI: 25). To talk about the primacy of perception does not mean putting sensations before the formal structures of judgment, as empiricism 
asserts. In fact, the intellect does not reconstruct a posteriori what is lacking in perception because there is nothing lacking: as expressed before, the object is given as present for me in its totality.

In any case, perception does not merely record the sensory stimuli that thought reconstructs thereafter in a mosaic of sensations, forming the perceived object. My organism is perceiving and at the same time interpreting those same stimuli, conferring on them, without any intellectual mediation, a certain perceptive configuration or form: "we see clearly why perception is not a phenomenon of the order of physical causality. We observe a response of the organism which interprets the stimuli and gives them a certain configuration" (PRI: 39). Thus, it is evident that perception is not a phenomenon belonging to the order of physical causality. In fact, as Ariela Battán states, “Merleau-Ponty instead of addressing the stimuli to determine in the sum of its parts the reason for this or that behavior, goes to the organism to verify its functioning. By taking as a point of support the organism can capture the diversity of the reaction in all its forms, and thus raise the insufficiency of linear causality as an explanatory resource" 2 (2004: 72-3). Perception is not caused or produced by certain stimuli, but rather the perceiving organism responds to them behaving in a certain way according to a precise perceptive style: "to me it seems impossible to hold that this configuration is produced by the stimuli. It comes from the organism and from the behavior of the organism in their presence" (PRI: 39).

\footnotetext{
2 My translation: “Merleau-Ponty en lugar de dirigirse a los estímulos para determinar en la sumatoria de sus partes la razón de tal o cual comportamiento, va al organismo a verificar su funcionamiento. Al tomar como punto de apoyo el organismo puede captar la diversidad de la reacción en todas sus formas, y plantear así la insuficiencia de la causalidad lineal como recurso explicativo". 
Initially, it is reasonable to talk about the primacy of perception because perception has the privilege of making me aware of the perceived object in its nascent stage. In other texts, Merleau-Ponty defines perception as the primary experience of knowledge (connaissance) in which the co-birth (con-naissance) of the perceived object occurs: "the experience of perception is our presence at the moment when things, truths, values are constituted for us; that perception is a nascent logos; that it teaches us, outside all dogmatism, the true conditions of objectivity itself" (PRI: 25). Perception teaches me the real conditions of the appearance of the percept's objectivity, revealing to me its being in its nascent stage and thus avoids reducing it to a mere sensation. Then, the perceived object is by definition present and living, and perception gives me back its being in such a way that it is possible to apply it to human relationships in order to create a new system of values - that is, a culture. It is not a matter of pointing out the perceptual experience as the primordial stage from which the world of culture is derived through a process of transformation or evolution of perception itself, but a matter of pointing out the level of experience that reveals the background of the problem that culture attempts to solve: "we call this level of experience primordial - not to assert that everything else derives from it by transformations and evolution [...] but rather that it reveals to us the permanent data of the problem which culture attempts to resolve" (PRI: 25).

In the article The Return to Perceptual Experience and the Meaning of the Primacy of Perception (1989), Theodore Geraets states that in the primordial experience of perception, objects are given as nascent processes that are as yet incomplete and have not yet been transformed into rigid and unmoving matter: "in this primordial experience everything is revealed 
as a meaning in the process of being born, which is to say that it is not yet completely finished, and has not as yet hardened and become unmoving" (1989: 33). That is why perception, according to Geraets, has the double privilege of unveiling the nascent conditions of the appearance of the present and living percept and the sensory data of knowledge on which it is feasible to construct a culture: "this twofold privilege, that of presence (living and present being) and that of being the foundation (the data and conditions)" (1989: 33). In other words, perception offers me an object whose sensory matter has already been impregnated with its living form: "[that] the matter of perception be pregnant with its form" (PRI: 15). However, although Merleau-Ponty himself affirms that perceptive experience constitutes the first stage of knowledge, he does not assert that culture can be reduced to the field of perception: "I did not mean to say that culture consists in perceiving. There is a whole cultural world which constitutes a second level above perceptual experience. Perception is rather the fundamental basis which cannot be ignored" (PRI: 33).

Therefore, what kind of primacy does perceptual experience play in relation to the world of culture? It is relevant to consider that perception, through the interpretation and configuration of sensory stimuli, establishes with the world of culture an above-all practical primacy and only in second place a theoretical-reflexive one. In effect, in response to the stimuli received, the organism does not produce the perceptual configuration of the object according to a physical causality. On the contrary, this configuration derives from the organism itself and from the type of practical response, or behavior, that it acts in the presence of these stimuli: "it comes from the organism and from the behavior of the organism in their presence" (PRI: 39). The organism is never completely 
passive before the perceived data: it does not limit itself to capturing the stimuli like an external recording camera that, distancing itself from the sensory world, catches them in their objectivity.

As previously explained, perception implies an interpretative behavior of the stimuli received that creates a culture, and reflection is an acquisition of this culture that does not suppress the relationships with the sensory world. Moreover, Merleau-Ponty states that in the perceptual experience, the root of each act, whether theoretical or practical, can be found in relation to human behavior: "reciprocally one could say that in a completely explicitated human perception we would find all the originalities of human life" (PRI: 40). Even those theoretical acts, such as imagination or ideation, which at first glance distance themselves from the sensory world to produce a world of cultural values, are characterized by the same creative and interpretative capacity that springs from and operates at the level of perceptual experience: "the same creative capacity which is at work in imagination and in ideation is present, in germ, in the first human perception" (PRI: 40).

Briefly, while it is true that man is capable of interpreting, transforming his life with the purpose of creating a cultural second-level world, he never leaves the cradle of sensory experience: "[we] have only replaced it [the subject] in the bed of the perceptible, which it transforms without ever quitting it" (PRI: 25). Although the perceptual consciousness is able to detach itself from the sensory world without ever abandoning it, there is still a blind spot in it, a limit that escapes from the perceptual consciousness itself and its vision of the world. Consciousness never possesses the world and itself totally, but through a residue or limit of the vision that belongs to it structurally, and that is the phenomenological 
condition of the being of the world and of its being in the world. Moreover, this is the difference between a phenomenological philosophy and a philosophy of the intellect by which the object is an absolute presence without gaps and without horizon: "but the essential difference between my point of view and that of a philosophy of the understanding is that, in my view, even though consciousness is able to detach itself from things to see itself, human consciousness never possesses itself in complete detachment [...]. Taking up a saying from Rimbaud, I said that there is a center of consciousness by which we are not in the world" (PRI: 40-1).

\section{The Perceptual Synthesis}

The operation that recognizes the existence of what is not given directly through perception is not an intellectual but a practical synthesis, a being-in-the-world that implies a certain behavior and tacit body gestures. In fact, as Renaud Barbaras states, "the study of behavior reveals rather what Merleau-Ponty already calls an existence, a being-in-theworld, a tacit relation to a presence rather than a possession of something in a representation (2004: 5). To give an example, it is possible for me to touch the invisible side of an object by following with my hands the lines suggested by the visible side or simply by pointing my hands towards the hidden part: "I can touch the lamp, and not only the side turned toward me but also the other side; I have only to extend my hand to hold it" (PRI: 14). The classic analysis of perception reduces sensory experience to the level of empirical proof, considering it as the only and really existing level. However, when I am aware of the context that surrounds me, I consider my being-in-the-world, my position in space and my own point of view, and see more of what I actually see. 
As noted above, the organism never records merely sensory data through its vision, for instance, simply a house or a street, but it sees the object already characterized by certain properties that derive from consideration of the surrounding environment: a country house or a building, an urban street or a mountain path: "I perceive before me a road or a house, and I perceive them as having a certain dimension: the road may be a country road or a national highway; the house may be a shanty or a manor" (PRI: 14). In addition, the things observed show themselves to be already configured and characterized by certain dimensions and colors that are determined by a practical relationship with the perceived object. The true dimensions and true colors of the perceived object, which actually differ from their apparent size and color, can be recovered only through a kinetic and tactile interaction involving the observer's corporeality: "these identifications presuppose that I recognize the true size of the object, quite different from that which appears to me from the point at which I am standing"' (PRI: 14).

It is widely believed that the real features of an object, such as size or color, can be derived from the analysis of its perceived appearances. So the real and objective size of the things observed should be established starting from their apparent size and through the mediation of the intellect. According to Merleau-Ponty, this procedure is not exact, mainly because it does not describe my perceptual experience. In fact, "the apparent size of which we are speaking is not perceived by me" (PRI: 14). This statement is so correct that to obtain the apparent size of one thing I should assume the existence of an objective and true visual field, prefabricated by the intellect and in which the size of the thing is perceived as apparent. However, such a visual field does not occur in the 
immediate perceptual experience, but is given as a result of an intellectual construction determined by necessary laws. Thus, when someone states that they perceive an object according to a deformed perspective or that they see its apparent size or color, they are already reducing the perceptual experience to the laws of geometrical perspective. It is even historically verifiable that the geometrical perspective of the visual field is not a necessary condition for perceiving a world of objects: "It is a remarkable fact that the uninstructed have no awareness of perspective and that it took a long time and much reflection for men to become aware of a perspectival deformation of objects" (PRI: 14-5).

The separation between apparent and true properties of the perceived object happens only after the perceptual act: it happens after the intellect has broken down the whole object into its parts and considers it as a mere accumulation of signs or a mosaic of sensations with no direct relation to their meaning. Perception does not offer signs that must later be deciphered and brought back to their meaning through an intellectual inference, because in perceptual experience, signs and meaning are not given separately: "thus there is no deciphering, no mediate inference from the sign to what is signified, because the alleged signs are not given to me separately from what they signify" (PRI: 15). Signs are always signs-of a meaning that precedes them and the apparent size is simply an isolated and abstract sign of an a posteriori meaning: the true size of geometric space. In the same way as the true size of an object does not derive from an analysis of geometric space occupied by it, neither is its true color deduced from that of the surrounding environment or how it is lit up. By way of illustration, if sunlight fills an environment during the day, the yellow of the artificial light would be perceived as a factor that alters the 
true chromatic configuration of the objects present in the environment. However, at sundown things will appear illuminated only by artificial light and their yellow will not be perceived as an altering factor, but as the background or the necessary condition that enables them to be seen. In short, the true color is not deduced from a chromatic analysis of the different profiles of the perceived object or by taking into account the type of lighting that characterizes the environment. In fact, it appears when it fades away: "the true color thus is not deduced, taking account of the lighting, because it appears precisely when daylight disappears" (PRI: 15).

What philosophical consequences do these considerations have? First, it should be observed, as mentioned above, that if the perceived object is a whole that precedes its parts, it is impossible to break it down into its elementary data and later reconstruct it, without denaturalizing it. Next, if the true color of an object does not derive from an a posteriori composition of its different chromatic aspects, or from an intellectual abstraction that separates natural and artificial illumination, perhaps I can affirm that the size and color familiar to me - not true or apparent, but familiar - are circumscribed from and through the point of view of my body, as the origin of the perceptive and practical field of possible behaviors: "This subject, which takes a point of view, is my body as the field of perception and action [pratique] - in so far as my gestures have a certain reach and circumscribe as my domain the whole group of objects familiar to me" (PRI: 16). The most important philosophical consequence, then, is that if perception recognizes the totality of the object immediately and prior to its possible decompositions without any conceptual mediation, the perceived object is not a mosaic of parts captured by the gaze and synthesized by a conceptual meaning: "we observe at once that it 
is impossible, as has often been said, to decompose a perception, to make it into a collection of sensations, because in it the whole is prior to the parts-and this whole is not an ideal whole. The meaning which I ultimately discover is not of the conceptual order" (PRI: 15).

Now, it is appropriate to consider that if the meaning of the object perceived were a concept, how could it be recognized in sensory experience? An intermediate element would be necessary between the sensory level and the conceptual knowledge, and then another mediation for intermediaries: it would be an infinite process that brings our memory to the old Aristotelian argument of the third man. Instead, "it is necessary that meaning and signs, the form and matter of perception, be related from the beginning and that, as we say, the matter of perception be pregnant with its form" (PRI: 15).

\section{The Ambiguous Structure of Perception}

One of the fundamental characteristics of perception directed to the external world is its continuous ambition to do something that, structurally, is not capable of doing. In what sense? What does perception offer me and how does its object show itself? Above all, the objects of perception are given through certain perspectives, profiles, gaps, fissures and boundaries that are unseen to my direct sight: the visibility of certain aspects of what is perceived also implies the invisibility of others. Thus, if the absent or invisible profiles lie in the same structure of the perceived object, the perception of an object does not consist in purely asserting its existence, but also in its negation, since the sensory object gives itself, in some way, by withdrawing. The percept's ways of giving are not defective, but rather are the only ones that allow me to perceive the object 
in its effective corporeality. As Luca Vanzago points out: "Merleau-Ponty, following Husserl, affirms that the only existential modality of the perceptive consciousness is its perspectivism"3 (2012: 28).

The way in which the perceived object gives itself in perspective is not generated by a failure of the perceptual system. Even the perceptual consciousness does not realize the perspectivism of the sensory object as a cognitive obstacle or an imperfection related to the existence of one's body: "but in immediate consciousness this perspectival character of my knowledge is not conceived as an accident in its regard, as an imperfection relative to the existence of my body and its proper point of view" (SB: 286). On the contrary, perspective does not appear as a subjective deformation of perceived objects, but as the essential condition for them to be visible. In addition, knowledge by profiles is not a downgrade in true knowledge, but a revelation of the hidden and inexhaustible richness of the perceived object, which finally appears as a thing. Thus, for example, the profiles of my desk do not appear directly to my perceptual consciousness as worthless appearances, but as appearances-of my desk. Each aspect shows something and refers to something else without exhausting the existence of the whole thing I see. In fact, "the things which I see are things for me only under the condition that they always recede beyond their immediately given aspects" (PRI: 16). The perceived object, receding continually beyond what can be seen, transcends its appearance and emerges as a thing for me, a phenomenon that provokes a questioning in the perceiver. According to Merleau-Ponty, "there is a paradox of immanence and transcendence in perception. Immanence, because the

\footnotetext{
${ }^{3}$ My translation: "seguendo lo Husserl delle Idee, Merleau-Ponty insiste sul fatto che la coscienza percettiva é questo o non é". 
perceived object cannot be foreign to him who perceives; transcendence, because it always contains something more than what is actually given" (PRI: 16).

The phenomenological structure of the perceived object is ambiguous: on the one hand the percept exists in itself insofar as its content transcends my perception, and on the other it is something for me as it is only given in flesh and blood, through aspects immanent and embodied in the perceiver. So, the relationship between the aspects given to me and the ones given in the percept itself is paradoxical: these aspects are unable to constitute the whole thing, and yet it is that very thing which reveals itself through and beyond all these aspects. Thus, the object of perceptual consciousness is configured as a paradoxical intertwinement of present and absent aspects: "these two elements of perception are not, properly speaking, contradictory. [...] The appearance of something, requires both this presence and this absence" (PRI: 16). In other words, the thing is real and exists in flesh and blood only by donating itself through its deformed perspectives through the point of view of the corporeal subject perceiving it. Those profiles which are present to me announce the whole thing in itself without exhausting it: the visible aspects of a thing are not signs indicating its invisible meaning, but each profile is given, already impregnated with its whole form. In short, perception is structurally ambiguous and paradoxically intertwined by materially visible and formally invisible aspects. However, it is interesting to note that neither the empiricist conception of perception, which reduces the object to a mosaic of sensations that derive from the succession of states of consciousness, nor intellectualism, which attempts to logically organize sensations through judgment, has grasped the underlying ambiguity that 
structurally characterizes perception: "neither the sequence of states of consciousness nor the logical organization of thought accounts for perception" (SB: 187).

Merleau-Ponty contradicts empiricism by arguing that the percept exceeds its sensory appearances: a cube is not reduced to what can be seen of it, as it is not possible to observe more than three sides at a time. In addition, the given profiles are structurally and reciprocally representative: the sides of a cube, as sides-of, refer to the whole of the object without necessarily implying an external relationship juxtaposed to them. Nor is the logical organization operated by an intellectual judgment able to justify the structure of perception. Such kind of organization would suppose the existence of a mind that contains its own object, corresponding to the perceived thing. However, the unity of the object does not derive from the correspondence of the perceived aspects to a mental meaning: the concordant multiplicity of sensory data is organized and configured autonomously. In order to account for the direct experience of the perceived object and not to reduce it to mere empirical data or to an intellectual concept, it is necessary to consider the percept as an entity in perspective: "thus, to do justice to our direct experience of things it would be necessary to maintain at the same time, against empiricism, that they are beyond their sensible manifestations and, against intellectualism, that they are not unities in the order of judgment, that they are embodied in their apparitions. The things in naive experience are evident as perspectival beings" (SB: 187). Things give themselves through the mediation of their profiles, which reveal their ambiguous and paradoxical structure, insofar as the unity of the percept transcends its 
sensory appearances, giving and embodying itself in them. So the object is "a transcendence which is nevertheless open to my knowledge" (SB: 187).

\section{The Universal Style of Perception}

As previously discussed, because of the ambiguity of the perceived object, it is impossible to reconstruct the percept by aggregating its profiles, and that the synthesis uniting them is practical and not intellectual. The intellectual synthesis only gives me possible objects, such as those represented by the imagination, or absolutely necessary and completely visible objects without shadows, such as the ideal figures of geometry. On the other hand, the object in flesh and blood is never merely a possible or necessary one, but is given to me deformed by the indefinite series of perspectives that derive from my point of view. Only under these conditions is it possible to define it as real. "What prohibits me from treating my perception as an intellectual act is that an intellectual act would grasp the object either as possible or as necessary. But in perception it is real; it is given as the infinite sum of an indefinite series of perspectival views in each of which the object is given but in none of which is it given exhaustively. It is not accidental for the object to be given to me in a deformed way, from the point of view [place] which I occupy. That is the price of its being real" (PRI: 15-6). It is possible to say that the perceptual synthesis, in its ambiguous and paradoxical structure, grounds the reality of the objects. However, under what conditions can perceptual synthesis be generated? Merleau-Ponty considers that the reality of the object is given only from this deforming perception, embodied by a point of view situated in a precise position. Perception does not simply put me in 
contact with the perceived object, but through my body it presents the object to me, constantly carrying me beyond it. Each aspect of the perceived thing represents another successive one in a never-ending practical synthesis, and which consists in a movement from the present and given sensory aspect to the potentially co-given one.

Furthermore, perceptual synthesis not only perceives the object as intertwined relationships of present and absent aspects, but also positions it on the horizon of all possible relationships: the world. In particular, perception not only evokes or represents what is currently inaccessible from my point of view, but rather proclaims it to be visible from another position or horizon. In this sense, perception acts a synthesis of horizon that, through my point of view, introduces me to the whole world. However, the synthesis of horizon is not a synthesis that makes me imagine all possible landscapes. The synthesis of horizon does not represent anything, but opens up all the possible landscapes that are "already there in the harmonious sequence and infinite unfolding of their perspectives" (PP: 384). My particular point of view does not limit my experience but indeed it is the privileged mode through which I am open to the totality of the natural world as the horizon of all horizons, the style of all styles. Thanks to my perceptive field I am present in the world around me and I co-belong to all the other landscapes that extend beyond my perspective. At the same time, this possibility of locating everything that transcends my perceptual vision is merely intentional and not effective. The landscape I see can announce to me what is lying behind the hill with a certain degree of indeterminacy. In this case, the only thing I am sure of with respect to its indeterminate remoteness is that there is something beyond what can be perceived in an abstract style. 
It is evident then, that beyond the present and perceived aspects of the object, on its internal and external horizon, there is a co-presence of $c^{-}$ perceived aspects. As an example, "when I see the bright green of one of Cézanne's vases, it does not make me think of pottery, it presents it to me. The pottery is there, with its thin, smooth outer surface and its porous inside, in the particular way in which the green varies in shade" (PP: 3845). However, all these given and co-given aspects are presented with the same perceptual style that ensures the unity of my experience of the object. Its unity is given and not built a posteriori, and is guaranteed by the natural world that is the horizon of all horizons, or the universal style of all possible perceptions. The correlate of the natural world, as the practical system of all perceptual visions of the world, is the body. For MerleauPonty the body is defined as that subject who embodies a point of view as a blind spot and origin of the perceptual field and of our possible behaviors. As Rossella Prezzo says: "what I see in perception is that, above all, things are presented to me and that I am present before them, in a mutual involvement, through that connection with the being that is my body"4 $^{\prime 2}$ (2004: 8). The body, with its sensory functions, circumscribes the perceptual field, and the object is an open totality whose reality is accessible only through the potentially infinite series of perceptual syntheses that concord with a certain style of self-giving by the object itself, that is the world. In conclusion, perception makes something present by situating it in a world - which is the totality of objects and the universal style of each possible perception - through the corporeal synthesis that reconfigures every detail on the correct perceptual horizon:

\footnotetext{
${ }^{4}$ My translation: "io che vedo, nella percezione, è innanzitutto che le cose mi si presentano e che io sono presente alle cose, in una mutua implicazione, attraverso quella giuntura con l'essere che é il mio corpo". 
"to perceive is to render oneself present to something through the body. All the while the thing keeps its place within the horizon of the world, and the structuration consists in putting each detail in the perceptual horizons which belong to it. But such formulas are just so many enigmas unless we relate them to the concrete developments which they summarize" (PRI: 42).

\section{References}

GERAETS, Theodore F. (1989). "The Return to Perceptual Experience and the Meaning of the Primacy of Perception". In Pietersma, Henry (Ed.), Merleau-Ponty: Critical Essays (31-43). Washington: University Press of America.

BALLABIO, Alessandro. (2016). Experiencia y creatividad en C. S. Peirce y M. Merleau-Ponty. Bogotá: Aula de Humanidades.

BARBARAS, Renaud. (2004). The Being of the Phenomenon. Merleau-Ponty's Ontology. Bloomington and Indianapolis: Indiana University Press.

BATTÁN, Ariela. (2004). Hacia una fenomenología de la corporeidad. Córdoba (Argentina): Editorial Universitas.

MERLEAU-PONTY, Maurice. (1963). The Structure of Behavior. Boston: Beacon Press.

- (1964). The Primacy of Perception and Its Philosophical Consequences. Evanston: Nothwestern Universtity Press.

- (2005). Phenomenology of Perception. London and New York: Routledge.

PREZZO, Rossella. (2004). "Il primato di un paradosso". In Prezzo, Rossella \& Negri, Federica (Eds.), Maurice Merleau-Ponty: Il primato della percezione e le sue conseguenze filosofiche (5-14). Milano: Edizioni Medusa.

VANZAGO, Luca. (2012). Merleau-Ponty. Roma: Carocci Editore. 